\title{
Faculty's experience of a formal mentoring programme: the perfect fit
}

\author{
Lizeth Roets ${ }^{1}$, Elsie Janse van Rensburg ${ }^{1}$, Johanna Lubbe ${ }^{2}$
}

1. University of South Africa, Health Studies; University of South Africa, Health Studies.

2. University of Pretoria. Department for Education Innovation.

\begin{abstract}
Background: The aging academic cohort in the faculty of health sciences necessitates transfer of knowledge and skills as a crucial component of sustainability. Formal mentoring programmes at higher education institutions aim to create a platform where experienced faculty can mentor newly appointed faculty to adjust to the context and gain knowledge and exposure. The formal mentoring programmes' structure and outcomes can create challenges and prevent the perfect fit between the mentor and mentee.

Purpose: The aim is to provide a description of the experiences of mentors and mentees of a formal mentoring programme in a higher education institution. This pilot study strives to provide recommendations to enhance mentorship experiences that facilitate adjustment and knowledge and skill transfer through the perfect fit.

Methods: A qualitative, descriptive case study was conducted as a pilot study. The case used was the formal mentoring programme. The unit of analysis was three purposefully selected faculty and researchers who were intimately involved in the mentoring process. Guided narrative reports were used and analysed by Tesch's content analysis.

Results: Three themes emerged namely, knowledge and skills transfer, mentoring programme and mentoring process.

Conclusion: The formal mentoring programme contributed positively to professional development, but posed challenges related to structural components. It is recommended that the structured mentoring programme be merged with informal mentoring to make it more authentic.
\end{abstract}

Keywords: Formal mentoring programme, the perfect fit.

DOI: https://dx.doi.org/10.4314/ahs.v19i2.49

Cite as: Roets L, van Rensburg EJ, Lubbe J. Faculty's experiences of a formal mentoring programme: the perfect fit. Afri Health Sci.2019;19(2): 2237-2242. bttps://dx.doi.org/10.4314/abs.v19i2.49

\section{Introduction}

Mentoring forms part of talent management in higher education institutions (HEIs) to develop and retain a cadre of faculty to fill leadership positions. Mentoring as part of a succession plan, involve current faculty as mentors to transfer their knowledge and skills to novices or newly appointed faculty. ${ }^{1}$ Succession plans are crucial in higher education institutions, especially faculty of health sciences, where a global shortage of health educators and health professionals exists.

\section{Corresponding author: \\ Elsie Janse van Rensburg, University of South Africa, Health Studies. \\ Email: jvrenes@unisa.ac.za}

Faculty members are an aging population. ${ }^{2}$ A new cadre of faculty needs to be mentored to take over educational roles, supervisory responsibilities and the generation of research outputs when seasoned faculty exits academia. Supervisory skills in need of transfer include online communication skills, principles and practice of constructive feedback and best practices to manage cultural and language diversity. ${ }^{3}$ The ability to present data and disseminate research findings through publications is a prerequisite for academic and professional success and needs to be fostered by the mentor. ${ }^{4}$ Numerous factors (such as high teaching and supervision load, emphasis on quality research outputs and personal experiences) contribute to seasoned faculty members regarding mentoring as an irritation. ${ }^{1}$

Mentoring in HEIs can take on the form of formal and informal programmes or a combination to combat the brain drain when seasoned faculty retire. However, the success of formal programmes differs, as there are many components of mentoring and mentorship that can cre- 
ate challenges. To understand the effectiveness of mentoring programmes, the experiences of mentors and mentees must be described. A qualitative, descriptive case study approach was used to address the aim of this pilot study to provide a description of the experiences of mentors and mentees within a formal mentoring programme at an HEI. Understanding of experiences was employed in this study to make recommendations to enhance the effectiveness of mentoring programmes.

A purposely-selected HEI, which initiated a formal mentoring programme to enhance knowledge and skills transfer formed the setting. The mentoring programme was structured with clear guidelines and processes and ran over a period of 12 months. Every mentor and mentee were bound to the written agreement and the objectives set for the 12 months of their mentorship relationship. Incentives were provided for mentees and mentors to enhance participation. The mentoring role was compulsory for faculty older than 60 years and formed part of their key performance areas.

Methods: The researchers' used interpretivism as a paradigmatic approach to reflect the multiple realities of each individual's experiences, meaning and context. ${ }^{5}$ A qualitative intrinsic descriptive case study design ${ }^{6}$ was applied as a pilot study to describe the experiences of the mentees and mentors within the formal mentoring programme at an HEI.

Principles of autonomy, privacy, confidentiality and beneficence were adhered to. ${ }^{8}$ Ethical approval was obtained from the Research Ethics Committee/IRB of the HEI (Ref HSHDC/543/2016). Participants chose volun- tary participation and could withdraw at any time without consequences. No harm was foreseen in participation. By completing and submitting their narrative reports via SurveyMonkey $^{\mathrm{TM}}$, participants provided voluntary consent to participate. The raw data received for analysis did not contain any identifiable personal data or the HEI's name. Trustworthiness of case study research was applied with a thick description of the data gathered. ${ }^{7}$ The account of the participants was verified to ensure accuracy and the completeness of the data. An audit trail was provided to enhance the verification of findings.

The unit of analysis was three purposively selected faculty working at an HEI who were involved both as mentors and mentees in a formal mentoring programme spanning a three-year period. The unit of analysis (the case) was a newly appointed senior faculty member with 27 years of teaching experience, one senior faculty member employed by the institution for five years with 10 years teaching experience and one newly appointed senior faculty member with 13 years teaching experience. Two participants reflected on cases where they were a mentee as well as a mentor, while one participant was a mentee with two different mentors. Narrative reports were used to collect data with five key questions posted on Survey Monkey ${ }^{\text {TM }}$. A total of 6 narrative reports were analysed through content analysis (Tesch's method of open coding') after data saturation was reached. All three researchers performed critical peer checks to validate the interpretations.

Results: Three themes were identified: knowledge and skills transfer, mentoring programme and mentoring process (see Table 1). 
Table 1: Experiences of a formal mentoring programme

\begin{tabular}{|l|l|}
\hline Themes & Categories \\
\hline 1. Knowledge and skills transfer & 1.1 Professional development \\
\hline 2.Mentoring programme & 2.1 Opportunities \\
\hline & 2.2 Challenges \\
\hline 3. Mentoring process & 3.1 Mentoring relationship \\
\hline & 3.2 Role clarification \\
\hline
\end{tabular}

\section{Theme 1: Knowledge and skills transfer}

Participants indicated that knowledge and skills were transferred and enhanced their professional development.

"Mentoring can be a valuable tool... a platform for professional growth... to seek advice and assistance from someone who is familiar with the context..."

Mentors need to develop novice educators in health sciences to fulfil the future needs of the health profession. High quality mentoring plays an important role to assist novice educators with quality research outputs, influencing evidence-based practice. ${ }^{10}$

The need for mentoring and the value thereof were linked to scholarship:

"I believe that we all can learn from one another... We need each other to strive and become better scholars..."

The mentee grows by gaining self-knowledge and best practice teaching competencies. ${ }^{11}$ These competencies include development of lesson and assessment plans and application of diverse teaching strategies. ${ }^{12}$ Participants related professional development to upscaling of skills and knowledge and adjustment to the new context. Unfortunately, not all mentoring experiences are positive. Mentorship can be demotivating and erode the self-confidence of the mentee. ${ }^{13}$

"Depending on the objective of the mentoring process, mentoring has the potential to be either crucial in role adaptation and upscaling of skills... or totally bumiliating and degrading..."

A positive experience and professional development can be facilitated through a mentoring relationship where the mentor and mentee agree on expectations and outcomes. ${ }^{13}$

"The newly appointed person might feel overwhelmed and out of their depth... A mentor can provide stability, anchoring the person during a stressful period of adjustment."

"It should be a voluntary relationship between two colleagues where one has something to offer to assist the other one to grow and develop. Mutual growth is the ideal."

As indicated by the participants, knowledge and skills transfer should ideally be mutually beneficial for the mentor and mentee and might be the institution's rationale for a formalised mentoring programme.

\section{Theme 2: Mentoring programme}

Participants indicated that the mentoring programme provided opportunities and challenges. Opportunities referred to structured expectations, outcomes and a platform for growth.

"Mentoring starts with one of the two parties identifying a need... the mentee needs support and guidance."

"...it was expected that newly appointed staff be mentored... The opportunities were that I expected to follow/be towed and that I experienced being pushed to be independent."

All the participants experienced challenges with the formalised structure of the programme. Challenges included limitations of the programme; reward system leading to paper-driven processes; not achieving the 'perfect fit'; and the unavailability of mentors. 
The process of needing to be a mentee before becoming a mentor was seen as a limitation.

"I did have a choice but was disappointed with the process. I wanted to mentor a colleague and be mentored myself, but the system did not allow me. I first had to be a mentee before I could be a mentor." "This [mentoring a senior person] was extremely awkward. My mentee was a newly appointed associate professor - two post grades above me. She has published extensively and ... did not need any mentoring...for her to become a mentor, she first needed to be a mentee...I was basically only enabling her to progress to the next stage... I understood from the beginning that this is actually a paper exercise."

Another limitation was the short time frame of 12 months for the programme.

"I had a specific outcome in mind and chose a person to assist me in achieving this outcome... I found that the outcome changed to be more achievable according to the timeframe of the programme...I felt let down... as I had to sacrifice the main outcome that I wanted to achieve."

The formal programme consisted of structured workshops, creating time constraints to consult with a mentor. "The [mentorship] programme was...very demanding and structured during the second exposure and I [was] forced to attend a certain number of workshops. The expectations of the programme were so rigorous that it limited my time resource with my mentor..." The mentoring programme was linked to a reward system in the performance appraisals of both mentee and mentor. This created a challenge as mentoring was seen as paper driven by the outcomes, sacrificing the personal connection of the mentorship relationship in the process. "...we had an agreement on paper and my experience was that my mentor was focused on achieving the deadlines on the paper more than connecting with me and my needs. I felt that I was needed as a tool for the mentor's performance reward...my mentorship encounters left me feeling disillusioned... I had a sense that there was an agenda (what is in it for me?) from the mentor's side that I was not aware of beforehand."

The self-determination theor ${ }^{14}$ describes internal and external locus of control as motivational factors for actions and behaviours. Intrinsic motivation is determined by the person self while extrinsic motivation is influenced by external factors, including a reward system. A reward system can shift the mentee's intrinsic motivation to an extrinsic motivation that is reward driven.
Participants indicated that achieving the 'perfect fit' between the mentor and mentee was crucial for a successful mentorship programme. This involved the setting of goals, and outcomes for both parties and their relationship.

"...I did [it] all on my own as my mentor said that I did not need mentoring. However, I would have loved new and innovative and relevant research support... I also need mentoring to prepare myself for NRF [National Research Foundation] rating, but my mentor is not rated... as a newly appointed person I did not know people good enough to choose an appropriate mentor..."

Another participant identified an informal mentor during the formal programme to find a mentor with a personality she felt a connection with.

"I've identified another mentor that I felt a connection with...not a mentor appointed in the mentor programme. This resulted in an informal mentoring process."

The participants emphasized the need for a perfect fit as illustrated by the quotes. The 'perfect fit' for a mentor could also be linked to the availability of the mentor.

"... accessibility was problematic at times. This left me stranded..."

The participants as indicated by the quotes and supported by literature highlighted that there is not a "one-size-fitsall approach" to mentoring. ${ }^{15}$ The mentoring process and style should be adapted to fit the needs of the mentor and mentee. ${ }^{16}$ Unfortunately, not all mentorship relationships are successful ${ }^{17}$ and an incompatible mentor and mentee result in a dysfunctional mentoring experience. It is crucial that a mentor should be approachable, accessible and authentic. The perfect fit entails 'good chemistry', understanding each other and feeling comfortable to work towards specified objectives. ${ }^{16}$

\section{Theme 3: The mentoring process}

Participants related the mentoring process to the mentoring relationship and role clarification. Participants indicated distance as disabling and support, guidance and trust as crucial components in the mentorship relationship.

"I experienced distance in our [mentee] relationship..."

Participants felt lost and in need for support when mentoring was ineffective.

"For me, it felt like me and another newly appointed person were 
like two blind mice, trying to mentor and support one another."

All the participants linked guidance with the mentorship relationship.

"I see mentoring as...two boats on the ocean... There are different stages... they can start off by the mentor sailing in front as she knows the context, while the mentee follows at a close distance...As the mentee becomes familiar... they can sail next to one another" Trust and honesty were crucial for the mentorship relationship to develop:

"...Without mutual trust, there will not be openness and willingness to learn, grow, question and discuss..."

A person-centred approach as a platform for the mentoring relationship include empathy, authenticity and respect. ${ }^{13}$ Participants indicated that clear role clarification during the initial phase of the mentoring process were vital.

"During my first exposure, I thought my role as mentee was to absorb as much as possible in terms of knowledge and skills... I saw my role as being a follower. [During my second exposure] I saw my role as... a partner..."

A mutual learning alliance is crucial in the mentorship relationship. ${ }^{17}$ A study showed that $92 \%$ of the respondents indicated their careers had been influenced by a mentor. ${ }^{18}$ They highlighted the importance of setting achievable performance goals to guide professional development.

\section{Discussion}

Findings indicated that the formal mentoring programme made a positive contribution to professional development and knowledge and skills transfer. However, the formalised programme did have challenges, specifically regarding the structured nature. One could argue that an organisation might be influenced by Taylor's classical organisational theory which addressed the principles of scientific management. ${ }^{19}$ Taylor indicated that managers (the organisation in this context) should provide a detailed performance structure in the formal mentoring programme to ensure positive outcomes of the mentorship relationship. This stepwise management process became known as Taylorism. ${ }^{19}$ As was the case with Taylor's theory, the emphasis on structure may prohibit creativity as reflected by the findings. Therefore, a more flexible model that facilitates the perfect fit and a more personalized approach to mentoring might be the solution.

\section{Conclusion}

Findings reflected participants' pre-conceived ideas, expectations and experiences regarding the process and outcomes of the mentoring programme. Some gained valuable inputs while the process disillusioned others.

Findings highlighted the importance of the "perfect fit" to enhance the positive experience of mentors and mentees and the success of the mentorship relationship.

Flexibility in structured mentoring programmes is recommended to accommodate informal mentoring in an attempt to continue the mentoring process after completion of the formal programme. Research is recommended on linking formal and informal mentoring to enhance scholarship in HEIs. It is recommended that the best of both formal and informal mentoring can provide a possible solution to address the draining of knowledge and skills while aging faculty members in health sciences are exiting the HEIs.

\section{Conflict of interest}

None declared.

\section{References}

1. Johnson WB. On Being a Mentor: A Guide for Higher Education Faculty. 2nd ed. New York: Taylor \& Francis, 2016:3-5.

2. Cannon S, Boswell C, Miller J. Best Practices for Mentoring Novice Academia Faculty Members. Sigma Theta Tau 26th International Research Congress. San Juan, Puerto Rico: San Juna, 2015. Retrieved from: http://hdl.handle. net/10755/601956 (accessed 12 March 2018).

3. Roets L. Supervision of doctoral and master's students in the ODL context in the field of tourism: an integrated review. AJHTL 2016; 5(4):1-14. PubMed. http//:www. ajhtl.com

4. Roets L, Maritz JE. Facilitating the development of higher order thinking skills (HOTS) of Novice nursing postgraduates in Africa. Nurse Education Today. 2017; 49:51-56. http://www.elsevier.com/nedt

5. Hudson L, Ozanne J. Alternative ways of seeking knowledge in Consumer research. Journal of Consumer Research. 1988; 14(4):237-249.

6. Grandy G. (2010). Intrinsic case study. In Mills, AJ, Durepos G, Wiebe E. (Eds.), Encyclopedia of case study research. Thousand Oaks, CA: SAGE Publications Ltd, 2010:500-501 doi: 10.4135/9781412957397.n183 
7. Rule P, John V. Your guide to case study research. Pretoria:Van Schaik Publishers, 2011:14-25.

8. Botma Y, Greeff M, Mulaudzi FM, Wright, SCD. Research in Health Sciences. Cape Town: Pearson Education, 2010:17-27.

9. Creswell JW. Research Design: Quantitative and Qualitative Approaches. 4th ed. Los Angeles: Sage, 2014:163. 10. Van Rensburg GH, Mayers P, Roets L. Supervision in higher education. TRENDS. 2016; 3(1): PubMed online http://dx.doi.org/10.14804/3-1-55.

11. Crossley M, Silverman RD. Reflections on mentoring. The Journal of Law, Medicine and Ethics. 2016; 44(1):76 -80. PubMed

12. Gilbert C, Womack B. Successful transition from expert nurse to novice educator. Teaching and Learning in Nursing. 2012; 7(3):100-102. Doi:https://doi.org/10.1016/j. teln.2012.01.0014

13. Cleaver J. How to mentor. The Chemical Engineer. 2016; 896:45-50.

14. Deci EL, Ryan RM. The "what" and "why" of goal pursuits: Human needs and self-determination of behaviours. Psychological Inquiry. 2000; 11(4):227-268. doi:10.1207/S15327965PLIII04_01.

15. Law AV, Bottenberg MM, Brozick AH, Currie JD, DiVall MV, Haines ST, Jolowsky C, Koh-Knox CP, Leonard GA, Phelps SJ, Rao D, Webster A, Yablonski, E. A checklist for the development of faculty mentorship programs. American Journal of Pharmaceutical Education. 2014; 78(5):1-11.

16. Hughes AJ, Fraser DM. There are guiding hands and there are controlling hands: Student midwives experience of mentorship in the UK. Midwifery 2011; 27:477-483. PubMed

17. Klinge CM. A conceptual framework for mentoring in a learning organization. Adult Learning. 2015; 26(4):160166. PubMed

18. Tareef AB. The relationship between mentoring and career development of higher education faculty members. College Student Journal 2013; 47(4):703-710.

19. Butts JB, Rich KL. Philosophies and Theories for Advanced Nursing Practice. $2^{\text {nd }}$ ed. United States of America: Jones \& Bartlett Learning, 2015:345. 